\title{
The Italian Society of Rheumatology clinical practice guidelines for the management of large vessel vasculitis
}

\author{
N. Ughi ${ }^{1,2}$, R. Padoan ${ }^{3}$, C. Crotti ${ }^{4}$, S. Sciascia ${ }^{5}$, G. Carrara ${ }^{2}$, A. Zanetti ${ }^{2,6}$, \\ D. Rozza ${ }^{2}$, S. Monti ${ }^{7}$, D. Camellino ${ }^{8}$, F. Muratore ${ }^{9}$, G. Emmi ${ }^{10}$, L. Quartuccio ${ }^{11}$, \\ S. Morbelli ${ }^{12}$, K. El Aoufy ${ }^{13,14}$, S. Tonolo ${ }^{15}$, R. Caporali ${ }^{4,16}$, S. De Vita ${ }^{11}$, \\ C. Salvarani ${ }^{9}$, M.A. Cimmino ${ }^{17}$ \\ 'Division of Rheumatology, Multispecialist Medical Department, \\ ASST Grande Ospedale Metropolitano Niguarda, Milan, Italy; \\ ${ }^{2}$ Epidemiology Research Unit, SIR, Società Italiana di Reumatologia, Milan, Italy; \\ ${ }^{3}$ Rheumatology Unit, Department of Medicine DIMED, Università di Padova, Padua, Italy; \\ ${ }^{4}$ Division of Clinical Rheumatology, ASST Pini-CTO, Milan, Italy; \\ ${ }^{5}$ Department of Clinical and Biological Sciences, Center of Research of Immunopathology and Rare Diseases \\ and SCDU Nephrology and Dialysis, Università di Torino, Turin, Italy; \\ ${ }^{6}$ Department of Statistics and Quantitative Methods, Division of Biostatistics, Epidemiology and Public \\ Health, Università di Milano-Bicocca, Milan, Italy; \\ ${ }^{7}$ Rheumatology Department, IRCCS Policlinico S. Matteo Fondazione, Università di Pavia, Pavia, Italy; \\ ${ }^{8}$ Division of Rheumatology, 'La Colletta' Hospital, Local Health Trust 3, Arenzano (GE), Italy; \\ ${ }^{9}$ Rheumatology Unit, Azienda Unità Sanitaria Locale-IRCCS di Reggio Emilia, Reggio Emilia, Italy; \\ ${ }^{10}$ Department of Experimental and Clinical Medicine, Ospedale Universitario Careggi, Florence, Italy; \\ ${ }^{11}$ Rheumatology Clinic, Department of Medicine, Università di Udine, ASUFC, Udine, Italy; \\ ${ }^{12}$ IRCCS Ospedale Policlinico San Martino, Genoa, Italy; \\ ${ }^{13}$ Department of Experimental and Clinical Medicine, Division of Rheumatology, \\ Università di Firenze, Florence, Italy; \\ ${ }^{14}$ Forum Italiano dei Professionisti Sanitari in Reumatologia (ForRheuma; Italian Forum of the Health \\ Professionals in Rheumatology), Milan, Italy; \\ ${ }^{15}$ Associazione Nazionale Malati Reumatici (ANMAR; National Association of Rheumatic Patients); \\ ${ }^{16}$ Department of Clinical Sciences and Community Health, Research Center for Adult and Pediatric \\ Rheumatic Diseases, Research Center for Environmental Health, Università degli Studi di Milano, Milan, Italy; \\ ${ }^{17}$ Research Laboratory and Academic Division of Clinical Rheumatology, Department of Internal Medicine, \\ Università di Genova, Genoa, Italy
}

\begin{abstract}
SUMMARY
Objective: Since of the last publication of last recommendations on primary large-vessel vasculitis (LVV) endorsed by the Italian Society of Rheumatology (SIR) in 2012, new evidence emerged regarding the diagnosis and the treatment with conventional and biologic immunosuppressive drugs. The associated potential change of clinical care supported the need to update the original recommendations.

Methods: Using the grading of recommendations assessment, development and evaluation (GRADE)-ADOLOPMENT framework, a systematic literature review was performed to update the evidence supporting the European Alliance of Associations for Rheumatology (EULAR) guidelines on LVV as reference. A multidisciplinary panel of 12 expert clinicians, a trained nurse, and a patients' representative discussed the recommendation in cooperation with an Evidence Review Team. Sixty-one stakeholders were consulted to externally review and rate the recommendations.

Results: Twelve recommendations were formulated. A suspected diagnosis of LVV should be confirmed by imaging or histology. In active GCA or TAK, the prompt commencement of high dose of oral glucocorticoids (40-60 mg prednisone-equivalent per day) is strongly recommended to induce clinical remission. In selected patients with GCA (e.g., refractory or relapsing disease or patients at risk of glucocorticoid related adverse effects) the use of an adjunctive therapy (tocilizumab or methotrexate) is recommended. In all patients diagnosed with TAK, adjunctive therapies, such as conventional synthetic or biological immunosuppressants, should be given in combination with glucocorticoids.

Conclusions: The new set of SIR recommendations was formulated in order to provide a guidance on both diagnosis and treatment of patients suspected of or with a definite diagnosis of LVV.
\end{abstract}

Keywords: Clinical Practice Guideline, recommendations, large vessel vasculitis, giant cell arteritis, Takayasu arteritis; management.
Corresponding author:

Nicola Ughi

Division of Rheumatology,

ASST Grande Ospedale Metropolitano

Niguarda, Milan

P.zza Ospedale Maggiore, 3

20162 Milano (MI), Italy

E-mail: nicola.ughi@ospedaleniguarda.it 


\section{INTRODUCTION}

L arge vessel vasculitis (LVV) encompasses the spectrum of primary vasculitis that predominantly affects the aorta and its major branches. The two major subtypes of LVV are giant cell arteritis (GCA) and Takayasu arteritis (TAK) $(1,2)$. They differ for the age of onset, with the former rarely occurring before the age of 50 years and the latter rarely after 50 years. Histopathologically, LVV is characterised by chronic granulomatous arterial inflammation, leading to vascular stenosis or aneurysm formation (3).

The estimated incidence of GCA in Europe in individuals aged over 50 years of age from a recent meta-analysis is $7.26(6.05-$ 8.47 ) per 100,000 individuals (4), making it the most common primary systemic vasculitis in adulthood $(5,6)$. In Italy, the overall age- and sex-adjusted incidence was estimated to be 5.8 per 100,000 persons aged $\geq 50$ years (7). The global pooled incidence is $10(9.22-10.78)$ per 100,000 people over 50 years, with the highest incidence in Scandinavian countries and North America (4). Conversely, TAK is less common than GCA. The incidence is 1-2 per million in Japan (8) and 0.4-1 per million in Europe (9), with a peak in the 15-30 year-old patients (10).

Over the last decade, new evidence emerged regarding the diagnosis as well as the treatment of LVV, exploring the role of both conventional and biologic immunosuppressive drugs and their potential to reduce glucocorticoid (GC) exposure while maintaining remission. Taking available evidence into account, between 2018 and 2021 the European Alliance of Associations for Rheumatology (EULAR) and the American College of Rheumatology (ACR) along with the British, Swedish and French Societies of Rheumatology revised and updated their recommendations for the management of LVV (11-16).

\section{NEED FOR ITALIAN GUIDANCE}

The last recommendations on primary LVV endorsed by the Italian Society of Rheuma- tology (SIR) were published in 2012 and focused on the (off-label) treatment with biological disease-modifying anti-rheumatic drugs (DMARDs) (17). In view of the absence of updated national guidelines dealing with the overall management of LVV, SIR was committed to develop a set of recommendations to provide a guidance for the clinical practice in Italy both on diagnosis and treatment of patients suspected of, or with a definite diagnosis of LVV in compliance with the requirements of the National Centre for Clinical Excellence, Quality and Safety of Care of the Italian National Institute of Health.

\section{Objective}

To provide evidence-based up-to-date recommendations for the diagnosis and treatment of patients suspected for or diagnosed with LVV in Italy.

\section{Target patient population}

Adult patients (age $\geq 18$ years) suspected of or diagnosed with LVV.

\section{Audience}

Physicians (rheumatologists, clinical immunologists, general practitioners, internists, geriatricians, vascular surgeons) and health professionals who manage patients with LVV in primary care, and hospital and community settings. Patients, policy makers and those responsible for commissioning care for patients with LVV in the Italian national health system (NHS).

\section{What is covered}

This guideline addressed diagnosis, treatment and follow-up of patients suspected of LVV or with a definite diagnosis of GCA and TAK.

\section{Areas that are not covered}

Primary vasculitis of the central nervous system, Cogan's syndrome, Behçet's disease, IgG4-related disease, ANCA-associated vasculitis, polyarteritis nodosa, Cryoglobulinemic vasculitis, $\operatorname{IgA}$ vasculitis, Kawasaki disease, Buerger's disease, and secondary vasculitis were not addressed in this guideline. 


\section{MATERIALS AND METHODS}

\section{Approach to guideline development}

The framework of Grading of Recommendations Assessment, Development and Evaluation (GRADE)-ADOLOPMENT (18) was used to identify the relevant existing guidelines and to adopt, to adapt at, or to produce de novo recommendations in observance of the handbook for the development of clinical practice guidelines for the National Guidelines System (revision 1.3.1 February 2019) (19) by the National Centre for Clinical Excellence, Quality and Safety of Care of the Italian National Institute of Health. The choice of the guideline topic, the plan of activities and the use of resources were approved by the board of directors of SIR as Scientific and Technical Committee. The final protocol for guideline development (version 1.1 December $19^{\text {th }}, 2019$ ) was approved by the Steering Committee of the SIR Study Group on Vasculitis.

\section{Assembly of the working groups}

On behalf of SIR the Developer (N.U.) and the Evidence Review Team (C.C., S.S., R.P., G.C., A.Z., D.R.) from the SIR Epidemiology Unit cooperated with a multidisciplinary panel of 12 expert clinicians in the fields of rheumatology, clinical immunology, and nuclear medicine (M.A.C., R.C., C.S., S.D.V., S.M, D.C., F.M., G.E., S.M., L. Q.), a trained nurse (K.E.A.), and a representative (S.T.) from the Italian National Association of Patients with Rheumatic Disease (ANMAR) by the means of e-mail discussions, web-meetings, and on-line surveys (via REDcap ${ }^{\circledR}$ ). The threshold of $75 \%$ of the participants was stated as a requisite to consider the discussions as well as the ratings to be valid for the purpose of development of the final recommendations.

\section{Stakeholder involvement}

A multi-disciplinary and multi-professional nationwide group of clinicians [55], health professionals [3] on behalf of FOR-RHeUMA and patient representatives [3] from ANMAR were invited to assess and rate the outcomes and the draft of these recommendations. These recommendations were developed without input from, or cooperation with, any pharmaceutical company nor industry.

\section{Defining the scope}

On the basis of a set of unstructured key health questions, the disease outcomes were assessed by the panel (February $3^{\text {rd }}$ $10^{\text {th }}, 2020$ ) and the stakeholders (February $28^{\text {th }}$-March $\left.13^{\text {th }}, 2020\right)$ and those whose rating was 'critical' or 'important' were used to guide the review of the existing recommendations which could be considered as a reference for the GRADE-ADOLOPMENT framework.

\section{Inclusion and exclusion criteria}

Guidelines addressing LVV from relevant international scientific societies such as the EULAR and the American College of Rheumatology (ACR) were considered if issued within the previous 3 years and those whose publication dated before 2017 were excluded.

For the search of evidence, clinical trials, observational studies, case series based on a number equal to or greater than 2 patients, and meta-analyses focusing on these studies were included without language restrictions. Editorials, commentaries, conference abstracts, narrative reviews, and case reports were excluded.

\section{Search strategy, data extraction and synthesis into the evidence profile}

The search of the literature was based on the PICO (population, intervention, comparator, outcome) frame of the questions which were adopted or adapted from two EULAR recommendations $(11,15)$ consistently to the panel's rating of the outcomes. In detail, for the definition of the disease activity states in LVV, the EULAR consensus was adopted (11). The evidence was retrieved from the systematic literature reviews (SLRs) informing these recommendations (20-22) and it was updated by performing two SLRs from the former end-of-search date (March 11 $\left.{ }^{\text {th }}, 2017\right)$ until February $25^{\text {th }}, 2020$ on

a) diagnosis, monitoring, and prognosis and

b) treatment. 
The following databases were used: Medline (via PubMed), Embase (via Ovid), and Cochrane Library (via Cochrane Central). The evidence review team performed the study selection and the data extraction (at least two members independently). The flow chart of the results of study selection is shown in Figure 1. The results were synthesized, meta-analysed and reported in summary of findings (SoF) tables grouped by disease and outcome.

\section{Critical appraisal of quality}

The evidence review team assessed the quality of the EULAR recommendations by using the on-line Appraisal of Guidelines Research and Evaluation (AGREE) II instrument (23) and a score as well as an overall assessment of the guideline were formulated per guideline. The quality of evidence retrieved from the systematic search was appraised by the evidence review team in accordance with the GRADE method by assessing the following domains: limitations (Risk of Bias Assessment), inconsistency, indirectness, imprecision and publication bias (by inspection of funnel plots and Egg- er's test). The risk of bias was assessed with the following tools: Quality Assessment of Diagnostic Accuracy Studies (QUADAS)-2 (24), Risk Of Bias In Non-randomised Studies - of Interventions (ROBINS)-I (25), Revised Cochrane risk-of-bias tool for randomized trials (RoB 2) (26), and the Quality In Prognosis Studies (QUIPS) (27) for diagnosis, treatment, and prognosis. Then, the overall quality of the evidence was graded as 'high', 'moderate', 'low', and 'very low', on the basis of expected impact on confidence of the estimate of the effect (Table I).

\section{From the evidence profile to the evidence-to-decision framework and the development of the recommendations}

The results listed in the SoF tables, and the quality appraisal were structured into the evidence-to-decision (EtD) framework, which served to conduct the debate on the recommendations among panel members via web-meetings (November $4^{\text {th }} / 9^{\text {th }}, 2020$ ). Hence, in light of the available evidence and the rarity of the diseases, a judgment on the strength of the recommendation was made and the statements were considered either

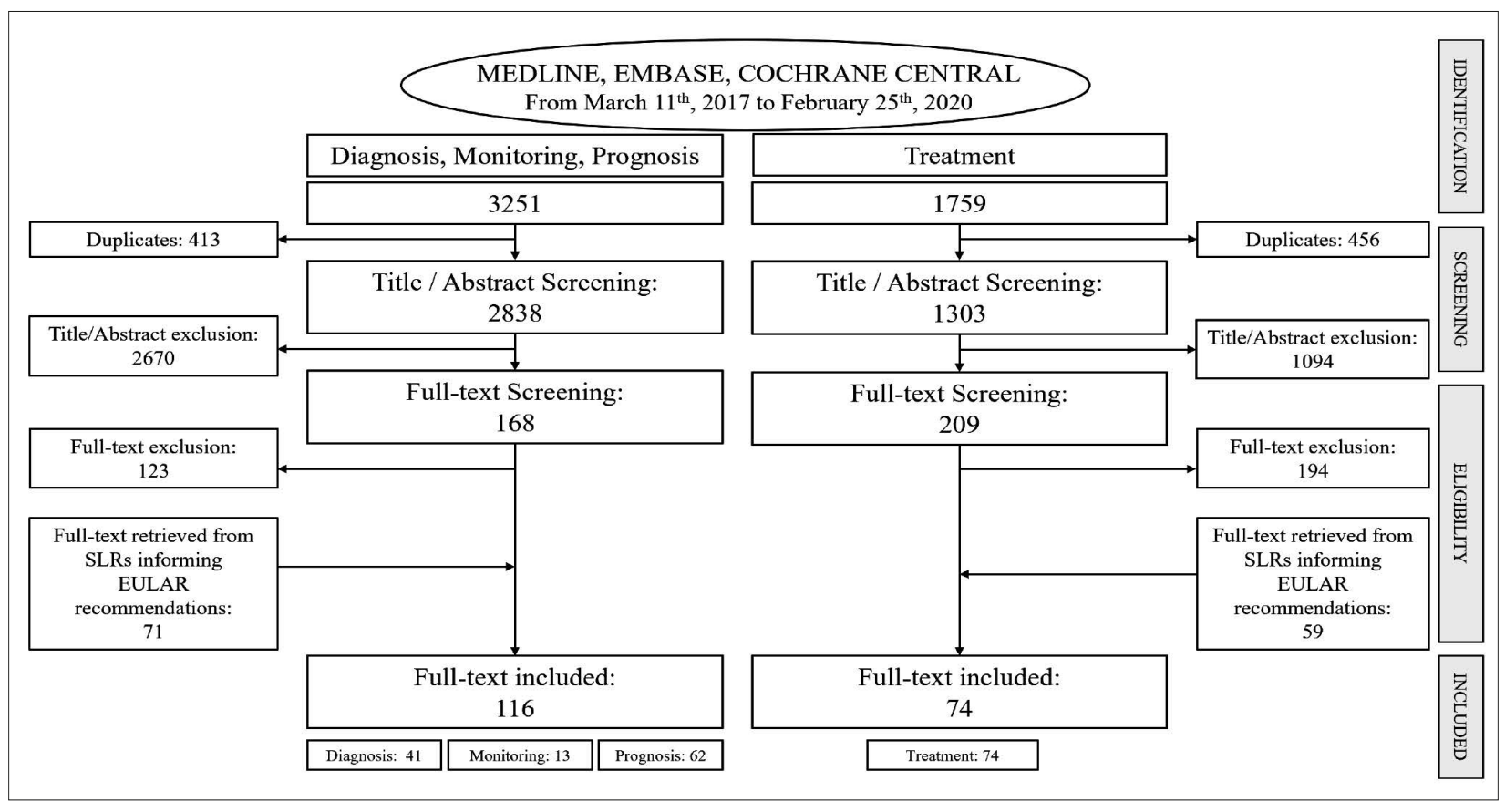

Figure 1 - Steps in the systematic reviews on diagnosis, monitoring, prognosis and treatment of large-vessel vasculitis. SLRs, systematic literature reviews; EULAR, European Alliance of Associations for Rheumatology. 
Table I - Guidance for the appraisal of the quality of evidence and strength of the recommendations in accordance with the Grades of Recommendation Assessment, Development and Evaluation (GRADE) approach.

\begin{tabular}{|l|l|l|l|}
\hline \multicolumn{4}{|l|}{ Quality of Evidence } \\
\hline High & Expected impact on confidence of the estimate of the effect \\
\hline Moderate & $\begin{array}{l}\text { "Further research is very unlikely to change our confidence in the estimate of effect". } \\
\text { "Further research is likely to have an important impact on our confidence in the estimate of effect and may change } \\
\text { the estimate". }\end{array}$ \\
\hline Low & $\begin{array}{l}\text { "Further research is very likely to have an important impact on our confidence in the estimate of effect and is likely } \\
\text { to change the estimate". }\end{array}$ & Policy makers \\
\hline Strength of the Recommendation & "Any estimate of effect is very uncertain". & $\begin{array}{l}\text { The recommendation can be } \\
\text { adapted as a policy in most } \\
\text { situations. }\end{array}$ \\
\hline Strong & $\begin{array}{l}\text { Mostients people in this situation would want } \\
\text { the recommended course of action and only } \\
\text { a small proportion would not. }\end{array}$ & $\begin{array}{l}\text { Most patients should receive } \\
\text { the recommended course of action. }\end{array}$ & $\begin{array}{l}\text { There is a need for substantial } \\
\text { debate and involvement of } \\
\text { stakeholders. }\end{array}$ \\
\hline Conditional & $\begin{array}{l}\text { The majority of people in this situation would } \\
\text { want the recommended course of action, } \\
\text { but many would not. }\end{array}$ & $\begin{array}{l}\text { Be prepared to help patients } \\
\text { to make a decision that is consistent } \\
\text { with their own values. }\end{array}$ & \\
\hline
\end{tabular}

strong or conditional in accordance with the view of patients, clinicians, and policymakers (Table I).

The AGREE reporting checklist was used for reporting the final version of this guideline (23).

\section{Approval of the recommendations and stakeholders' consultations}

The members of the panel rated the draft of the recommendation by using a 1 (worst)to-9(best) score via an on-line survey (December $11^{\text {th }}-21^{\text {st }}, 2020 ; 11 / 12$ respondents, response rate $92 \%$ ). An average score $>7$ was defined a priori to consider the final recommendation to be valid and approved for clinical practice. A number of 61 stakeholders were consulted to externally review and rate (1-to-9-point scoring) the draft of the recommendations via an online survey (January $14^{\text {th }}$ to $27^{\text {th }}, 2021$ ). The comments from the respondents $(\mathrm{n}=22$, response rate $36 \%$ ) were considered for the development of the final recommendations. Finally, the recommendations were externally reviewed by three independents referees who were not involved in the guideline development and submitted to the National Centre for Clinical Excellence, Quality and Safety of Care of the Italian National Institute

Table II - The final set of recommendations of the Italian Society of Rheumatology for the diagnosis, monitoring and treatment of large-vessel vasculitis.

\begin{tabular}{|c|c|c|c|c|}
\hline & The final set of 12 recommendations & QoE & SoR & $\begin{array}{c}\text { LoA, } \\
\text { mean (sd) }\end{array}$ \\
\hline & \multicolumn{4}{|l|}{ Diagnosis } \\
\hline 1 & $\begin{array}{l}\text { A) A In patients with clinically suspected cranial LVV, an early confirmatory diagnostic test } \\
\text { (imaging and/or biopsy) is strongly recommended. } \\
\text { B) The use of colour-duplex ultrasonography for temporal artery or high-resolution } \\
\text { magnetic resonance for temporal or other cranial arteries is strongly recommended } \\
\text { for clinical suspicion of cranial GCA. }\end{array}$ & Low & Strong & $8.3(0.8)$ \\
\hline 2 & $\begin{array}{l}\text { A) In patients with clinically suspected LVV with involvement of the aorta and/or } \\
\text { the extracranial arteries an early confirmatory diagnostic imaging test is strongly } \\
\text { recommended. } \\
\text { B) The use of PET, MR angiography, CT angiography or colour-duplex ultrasonography } \\
\text { is strongly recommended to evaluate the involvement of the aorta and/or other } \\
\text { extracranial arteries. }\end{array}$ & Low & Strong & $8.5(0.8)$ \\
\hline
\end{tabular}




\begin{tabular}{|c|c|c|c|c|}
\hline \\
\hline & The final set of 12 recommendations & QoE & SoR & $\begin{array}{l}\text { LoA, } \\
\text { mean (sd) }\end{array}$ \\
\hline & \multicolumn{4}{|l|}{ Monitoring } \\
\hline 3 & $\begin{array}{l}\text { A) In patients diagnosed with GCA and suspicion of relapse, clinical findings and ESR and/ } \\
\text { or CRP levels are strongly recommended for the assessment of disease activity. } \\
\text { B) The use of imaging (PET) is conditionally recommended against in those in whom } \\
\text { the clinical suspicion of relapse is absent. } \\
\text { C) Imaging may be considered to confirm or exclude the suspicion of disease relapse } \\
\text { on the basis of the clinical findings and ESR and/or CRP levels }\end{array}$ & Low & $\begin{array}{l}\text { Strong (A, B) / } \\
\text { Conditional (C) }\end{array}$ & $7.8(1.0)$ \\
\hline 4 & $\begin{array}{l}\text { A) In patients diagnosed with GCA, the use of imaging (MR angiography, CT angiography } \\
\text { or colour-duplex ultrasonography) is strongly recommended for the assessment of } \\
\text { structural damage, such as vascular stenosis, occlusion, dilatation and/or aneurysms, } \\
\text { as part of patient's follow-up. } \\
\text { B) The choice of the imaging method and the timing of the assessment are conditionally } \\
\text { recommended to be scheduled on an individual basis. }\end{array}$ & Very Low & $\begin{array}{c}\text { Strong (A) / } \\
\text { Conditional (B) }\end{array}$ & $7.0(2.1)$ \\
\hline \multirow[t]{2}{*}{5} & $\begin{array}{l}\text { A) In patients with a diagnosis of TAK and suspicion of relapse, clinical findings and ESR } \\
\text { and/or CRP levels are strongly recommended for the assessment of disease activity. } \\
\text { B) The use of imaging (MR angiography, CT angiography, PET or colour-duplex } \\
\text { ultrasonography) is strongly recommended for the assessment of disease activity } \\
\text { and/or structural damage, such as vascular stenosis, occlusion, dilatation } \\
\text { and/or aneurysms, as part of patient's follow-up. } \\
\text { C) The choice of the imaging method and the timing of the assessment are conditionally } \\
\text { recommended to be scheduled on an individual basis. }\end{array}$ & $\begin{array}{l}\text { Low (A) } \\
\text { to Very Low } \\
(B, C)\end{array}$ & $\begin{array}{l}\text { Strong (A, B) / } \\
\text { Conditional (C) }\end{array}$ & $7.9(1.0)$ \\
\hline & \multicolumn{4}{|l|}{ Treatment } \\
\hline 6 & $\begin{array}{l}\text { In active GCA } \mathrm{G}^{\S} \text { or TAK }{ }^{\dagger} \text {, the prompt commencement of high dose of oral glucocorticoids } \\
\text { ( } 40-60 \mathrm{mg} \text { prednisone-equivalent per day) is strongly recommended to induce clinical } \\
\text { remission. }\end{array}$ & $\begin{array}{l}\text { Moderate } \text { to }^{\S} \\
\text { Very Low }\end{array}$ & Strong & $8.2(1.2)$ \\
\hline 7 & $\begin{array}{l}\text { In patients suspected to have cranial GCA, the fast-track pathway, based on quick clinical } \\
\text { and ultrasonographic evaluation, is conditionally recommended in order to reduce the risk } \\
\text { of permanent visual impairment. }\end{array}$ & Moderate & Conditional & $7.7(1,3)$ \\
\hline 8 & $\begin{array}{l}\text { In patients diagnosed with } \mathrm{GCA}^{\S} \text { or } \mathrm{TAK}^{\dagger} \text { who experience a disease relapse, the } \\
\text { reinstitution or the dose escalation of the glucocorticoid therapy is strongly recommended. }\end{array}$ & $\begin{array}{l}\text { Moderate } \\
\text { to Very Low }\end{array}$ & Strong & $8.4(0.8)$ \\
\hline 9 & $\begin{array}{l}\text { In selected patients with GCA with refractory or relapsing disease or at risk } \\
\text { of glucocorticoid related adverse effects, the use of an adjunctive DMARDs } \\
\text { (tocilizumab or methotrexate) is strongly recommended. }\end{array}$ & Moderate & Strong & $7.7(0.8)$ \\
\hline 10 & $\begin{array}{l}\text { In all patients diagnosed with TAK, the use of adjunctive therapies, such as conventional } \\
\text { synthetic or biological DMARDs, in combination with glucocorticoids is conditionally } \\
\text { recommended. }\end{array}$ & Very Low & Conditional & $7.5(2.1)$ \\
\hline 11 & $\begin{array}{l}\text { In patients with GCA, the routine prescription of antiplatelet or cholesterol-lowering } \\
\text { agents, such as statins, unless necessary for the cardiovascular risk, is conditionally } \\
\text { not recommended. }\end{array}$ & Very Low & Conditional & $7.0(2.4)$ \\
\hline 12 & $\begin{array}{l}\text { In patients diagnosed with TAK, revascularization procedures (open surgery or } \\
\text { endovascular procedures) are conditionally recommended in phase of stable remission. }\end{array}$ & Very Low & Conditional & $7.6(1.8)$ \\
\hline
\end{tabular}

LVV, large vessel vasculitis; GCA, Giant cell arteritis; TAK, Takayasu arteritis; CRP, C-reactive protein; ESR, erythrocyte sedimentation rate; DMARDs, disease-modifying antirheumatic drugs; MR, magnetic resonance; PET, positron emission tomography; CT, computed tomography; QoE, Quality of evidence; SoR, strength of the recommendation; LoA, level of agreement between the members of the panel; sd, standard deviation.

of Health for endorsement. These recommendations were officially released in the National Guidelines System in August $5^{\text {th }}$, 2021 (19). For further details about the methodology and the supporting evidence not described here, reference is made to the above-mentioned document.

\section{RESULTS}

\section{Key to Understanding This Guidance}

Each recommendation is reported with the quality of evidence (QoE), strength of the recommendation (SoR), and level of agreement (LoA) between the members of the 
panel (Table II). The text supporting each recommendation is structured as follows:

Supporting evidence. List of the evidence. From evidence to recommendation. Panel's discussion based on the evidence and the clinical experience used to develop the recommendation.

The algorithms which summarize the pathways for the diagnosis of patients with (suspected) LVV and their management are shown in Figures 2 and 3, respectively.

\section{RECOMMENDATIONS}

\section{Recommendations for diagnosis}

\section{RECOMMENDATION 1:} diagnosis of cranial $\mathrm{LVV}$

A) Patients with clinically suspected cranial LVV should have an early confirmatory diagnostic test (imaging and/or biopsy).

B) Colour-duplex ultrasonography for temporal artery or high-resolution magnetic resonance for temporal or other cranial arteries, are strongly rec- ommended for clinical suspicion of cranial GCA.

QoE: Low; SoR Strong: D; LoA, mean (sd), 8.3 (0.8).

\section{Supporting evidence}

Every effort should be made to timely confirm a suspected diagnosis of LVV. Temporal artery biopsy (TAB) is considered the reference standard for diagnosis. No retrieved studies evaluated a composite outcome including imaging and/or biopsy. Studies with a reference standard other than clinical diagnosis (without formal criteria), ACR classification criteria and/or temporal artery biopsy result were not included in our analysis. Retrieved studies have shown that neither Colour-duplex ultrasonography (CDU) nor magnetic resonance (MR) are $100 \%$ sensitive. Five observational studies (28-32) investigated the diagnostic performance of CDU compared to TAB in patients with clinical suspicion of cranial GCA, resulting in an overall sensitivity of 0.83 (95\% CI $0.76-0.90)$ and specificity of

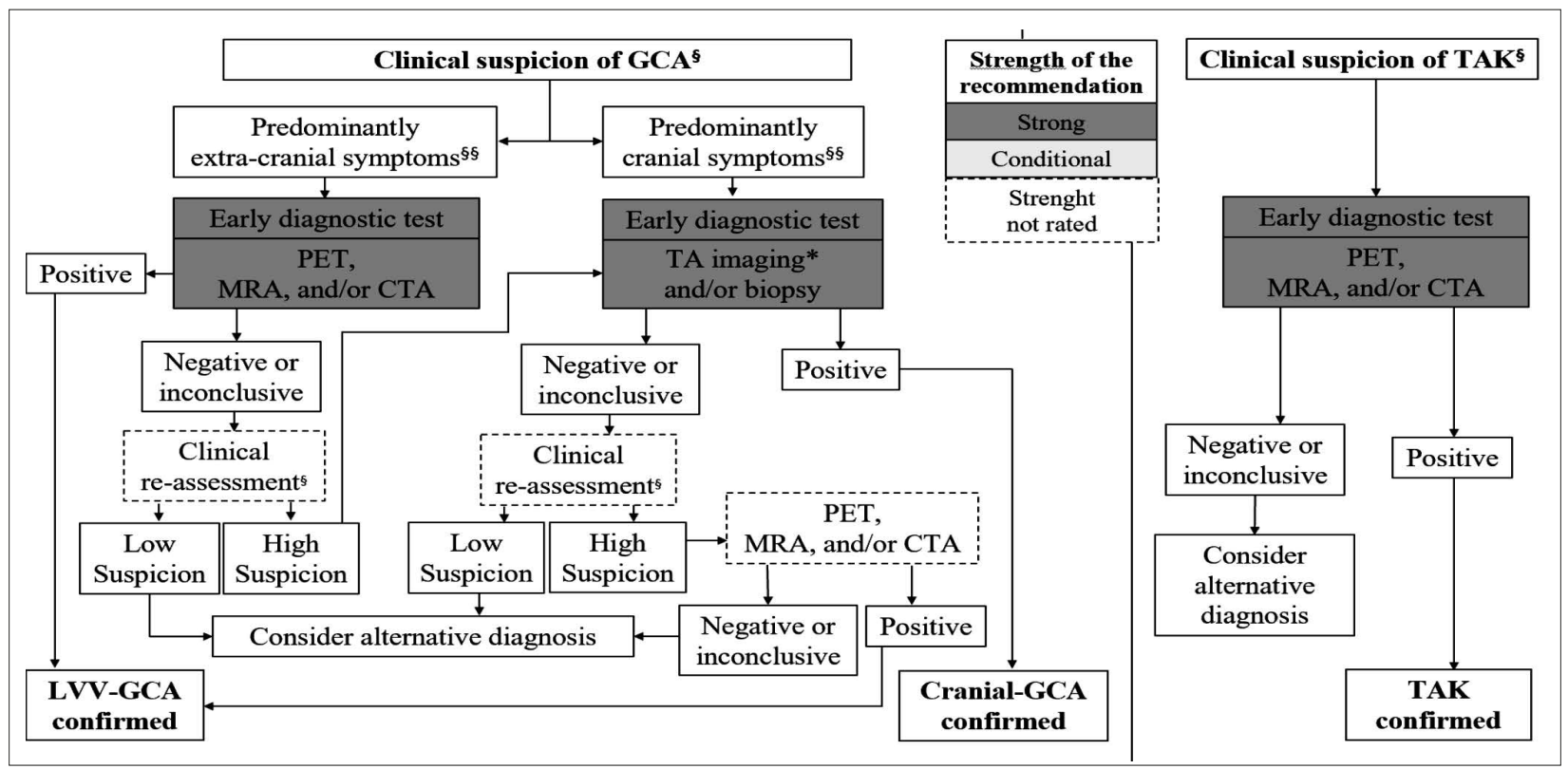

Figure 2 - The diagnosis of giant cell arteritis and Takayasu arteritis according to the recommendations of the Italian Society of Rheumatology.

*colour-duplex ultrasonography and/or high-resolution magnetic resonance; ${ }^{*}$ clinical findings suspicious for active large vessel vasculitis are listed in Table III; \$sthese pathways may not be mutually exclusive, and the diagnostic tests may be performed in parallel. GCA, giant cell arteritis; TAK, Takayasu arteritis; PET, positron emission tomography; CT, computed tomography; CTA, computed tomography angiography; MRA, magnetic resonance angiography; TA, temporal artery; LVV, large vessel vasculitis. 


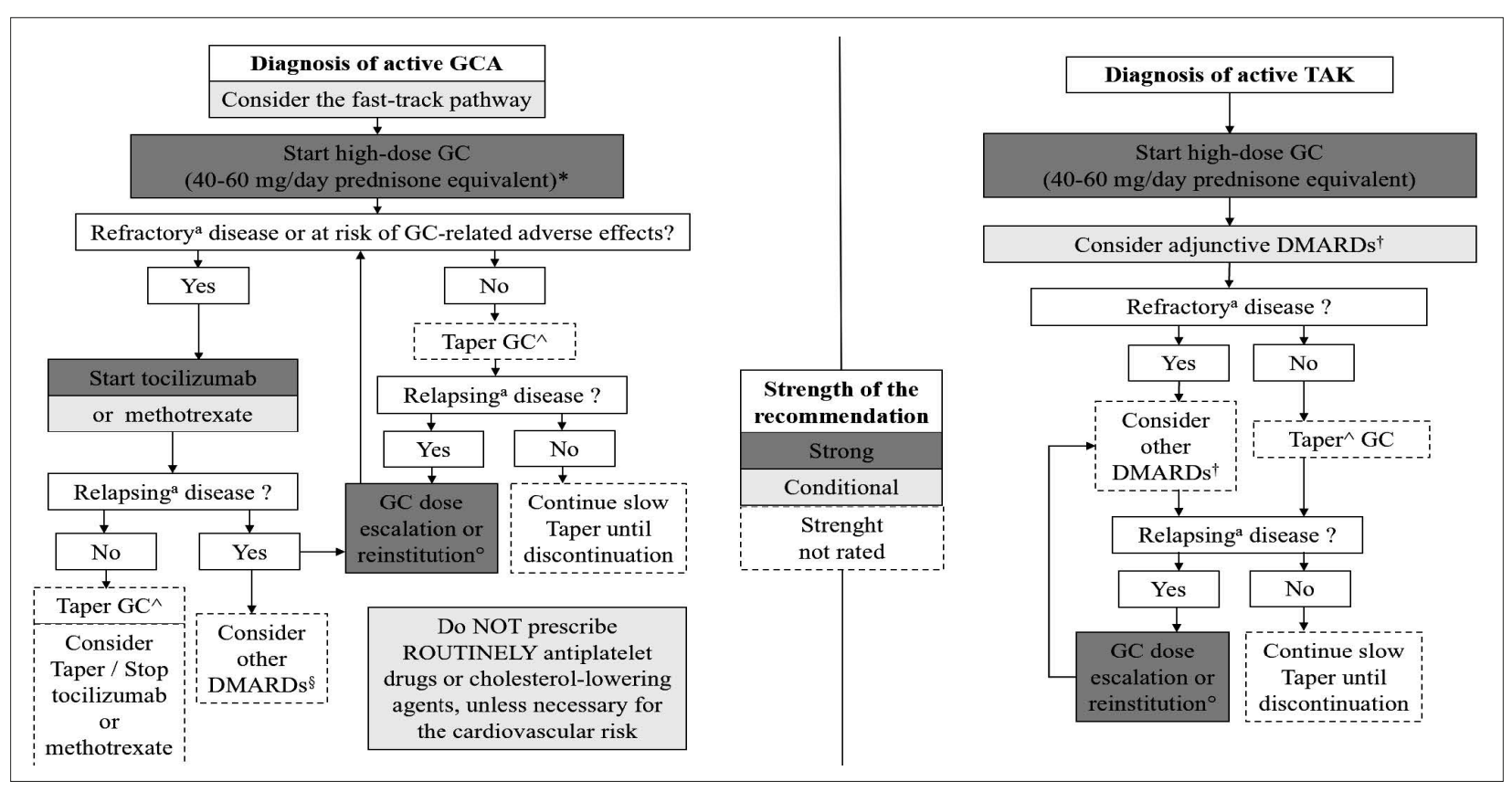

Figure 3 - The treatment of giant cell arteritis and Takayasu arteritis according to the recommendations of the Italian Society of Rheumatology.

*intravenous route of administration of GC (250-1000 mg prednisone equivalent daily for 1 to 3 days) may be considered, particularly in those patients with visual symptoms; athe key clinical sign and symptoms suspicious for active disease are listed in Table III; ^on the basis of experts' opinion, the following schedule is suggested: GC to 15-20 mg/day prednisone equivalent within 2-3 months and then to $\leq 5-10 \mathrm{mg} /$ day after one year; ${ }^{\circ} 40-60 \mathrm{mg} /$ day prednisone equivalent or last effective dose; sleflunomide, azathioprine, cyclophosphamide, abatacept; ${ }^{\dagger}$ methotrexate, mycophenolate mofetil, leflunomide, cyclophosphamide, tocilizumab, tumor necrosis factor (TNF)-inhibitors; GCA, giant cell arteritis; TAK, Takayasu arteritis; GC, glucocorticoids; DMARDs, disease-modifying anti-rheumatic drugs.

0.76 (95\% CI 0.69-0.84). The risk of bias was generally low. A prospective multicentre cohort study $(\mathrm{n}=381)$ demonstrated the feasibility and cost-effectiveness of a strategy including CDU against TAB (33). Finally, a recently published prospective multicentre study including 106 patients, confirmed high diagnostic accuracy of CDU performed by well-trained ultrasonographers in suspected GCA, with a sensitivity of $94 \%$ and specificity of $84 \%$ (34).

Four studies (35-38) evaluated the sensitivity and two studies assessed specificity $(37,39)$ of high-resolution MR, reporting values raging $0.80-0.92$ and $0.78-0.85$, respectively. Due to the risk of bias and heterogeneity in the study, the overall QoE was assessed as low for MR.

Imaging test should be performed as early as possible after commencement of treatment, especially within one week, because treatment with glucocorticoids rapidly reduces the sensitivity of the examination $(33,40)$.

\section{From evidence to recommendation}

This recommendation is broad in its nature and aims to provide a framework for the subsequent specific recommendations on different imaging modalities. The panellists recognised that many physicians still consider TAB as the gold standard test for the diagnosis of GCA. For this reason, regardless the low quality of the evidence, this recommendation was judged to be strong. An alternative diagnosis should be considered (Figure 2) in the diagnostic work up for patients with both biopsy and imaging results not compatible with current disease definitions.

In subjects with suspected GCA presenting predominantly with cranial symptoms, 
CDU should be the primary imaging test because of a high QoE of good test performance paralleled by easy access, absence of radiation or other procedural risks and the relative low costs as compared with other modalities. Moreover, CDU can be extended to accessible extra-cranial arteries. However, a well-trained sonographer, possibly from a referral centre, should perform CDU. Regardless the lower QoE, the panellists agreed that high resolution MR of superficial cranial arteries can be considered as an alternative to $\mathrm{CDU}$. The main limitations of MR are restricted availability, costs and possible adverse effects of contrast agents. Those aspects might be counterbalanced by the higher standardisation degree of data acquisition over CDU and the possibility to investigate multiple cranial and extracranial arteries including the aorta at the same time.

\section{RECOMMENDATION 2:}

\section{diagnosis of extra-cranial LVV}

A) Patients with clinically suspected LVV with involvement of the aorta/extracranial arteries should have an early imaging confirmatory diagnostic test.

B) The use of PET, MR angiography, CT angiography or colour-duplex ultrasonography is strongly recommended to evaluate the involvement of the aorta/extracranial arteries.

QoE: Low; SoR Strong: D; LoA, mean (sd), $8.5(0.8)$.

\section{Supporting evidence}

Four observational studies (19) investigated the diagnostic performance of MR angiography (MRA) in patients with clinical suspicion of extra cranial involvement, resulting in an overall sensitivity of 0.88 (95\% CI $0.82-0.94)$ and specificity of $0.82 \%$ (95\% CI $0.77-0.87$ ). The risk of bias was generally low.

The sensitivity and specificity of positron emission tomography (PET) were investigated in six studies (19). When pooled together, a sensitivity of $0.72(95 \%$ CI 0.61 0.83 ) was found and counterbalanced by high specificity 0.96 (95\% CI 0.93-0.99).

The best imaging technique for patients with suspected extra-cranial LVV is still unclear and depends on local settings and expertise. A recent study demonstrated high diagnostic accuracy of axillary artery ultrasound for diagnosis of extra-cranial LVV, with a sensitivity of $76 \%$ and a specificity of $100 \%$, further suggesting priority of ultrasound over PET as the first-line diagnostic test in patients with suspected extra-cranial LVV (41).

The examination of large vessels should be conducted early, best within a time frame of one week, because the diagnostic accuracy is rapidly compromised by glucocorticoid treatment $(33,40)$.

\section{From evidence to recommendation}

This broad recommendation provides a framework for the subsequent specific guidance on a timely diagnosis using different imaging modalities. Regardless the low quality of the evidence, this recommendation was judged to be strong by the panellists. The inclusion of CT angiography (CTA) or CDU in this recommendation was based on expert opinion. The absence of independence between index test and the reference standard, the GC therapy, the circular application of different criteria for LVV, and the relatively small sample size of the included studies can explain the observed degree of heterogeneity in imaging methods. Regardless the low QoE, the panellists agreed that PET, MRA, CTA or CDU should be considered as alternative imaging modalities to evaluate the involvement of the aorta/extra-cranial arteries.

\section{Recommendations for monitoring}

\section{RECOMMENDATION 3:} assessment of disease activity in GCA

A) In patients diagnosed with GCA and suspicion of relapse, clinical findings and ESR and/or CRP levels are strongly recommended for the assessment of disease activity.

B) The use of imaging (PET) is conditionally recommended against in those in whom the clinical suspicion of relapse is absent.

C) Imaging may be considered to confirm or exclude the suspicion of disease relapse on the basis of the clinical findings and ESR and/or CRP levels. 
QoE: Low; SoR: Strong (A, B) / Conditional (C); LoA mean (sd): 7.8 (1.0).

\section{Supporting evidence}

A limited number of studies focused on PET or laboratory analysis, such as ESR and CRP, for detection of systemic inflammatory response related to disease relapse. In a low-risk-of-bias study on 111 patients, the sensitivity of PET to assess disease activity during follow-up showed to be good $(0.85,95 \%$ CI $0.70-0.94)$, but its specificity was 0.42 (95\% CI $0.31-0.55)$ and a high proportion of false positives was observed (55\%) (42). In a study on 80 patients diagnosed with either GCA or TAK, the overall sensitivity and specificity of PET, ESR and, CRP to assess disease activity were respec-

Table III - A list of clinical findings which could be associated with the diagnosis of active giant cell arteritis or Takayasu arteritis and the disease relapse during the follow-up.

\begin{tabular}{|c|c|c|}
\hline \multicolumn{3}{|c|}{ Clinical assessment at or near diagnosis } \\
\hline Key features & GCA & TAK \\
\hline Symptoms & $\begin{array}{l}\text { - Constitutional symptoms (weight loss, fever, } \\
\text { night sweats). } \\
\text { - Headache (usually located over the temples } \\
\text { but can also be also be frontal, occipital, unilateral, } \\
\text { or generalized) } \\
\text { - Jaw and/or tongue claudication } \\
\text { - Visual Changes (transient visual loss, diplopia, and } \\
\text { permanent vision loss) } \\
\text { - PMR symptoms (aching and morning stiffness of the } \\
\text { shoulder and hip girdles, in the neck, and in the torso) } \\
\text { - Myalgia, arthralgia } \\
\text { - Limb claudication. }\end{array}$ & $\begin{array}{l}\text { - Constitutional symptoms (weight loss, low-grade fever, } \\
\text { fatigue) } \\
\text { - Limb claudication } \\
\text { - } \text { Carotidynia } \\
\text { - } \text { Gastrointestinal symptoms (abdominal pain, particularly } \\
\text { postprandial pain, diarrhoea, and gastrointestinal } \\
\text { hemorrhage may result from mesenteric artery ischemia) } \\
\text { - Neurologic symptoms (lightheadedness, vertigo, syncope, } \\
\text { orthostasis, headaches, convulsions, and strokes may } \\
\text { result from carotid and vertebral arteries involvement). } \\
\text { - Visual changes (transient visual loss, diplopia) } \\
\text { - Myocardial infarct, angina } \\
\text { - Shortness of breath } \\
\text { - Myalgia, arthralgia }\end{array}$ \\
\hline $\begin{array}{l}\text { Findings } \\
\text { on clinical } \\
\text { examination }\end{array}$ & $\begin{array}{l}\text { - Erythematous, nodular, or swollen scalp arteries } \\
\text { - Absent or weak peripheral pulse(s) } \\
\text { and anisosphygmia at the upper limbs } \\
\text { - Decreased temporal artery pulsations } \\
\text { - Large artery bruits (particularly in the axilla) } \\
\text { - Ophthalmoscopic abnormalities* }\end{array}$ & $\begin{array}{l}\text { - Absent or weak peripheral pulse(s) and anisosphygmia } \\
\text { - Hypertension (>140/90 mm Hg) } \\
\text { - Arterial bruit (in patients with stenoses, bruits are usually } \\
\text { audible over the subclavian arteries, brachial arteries, } \\
\text { carotid arteries, and abdominal vessels } \\
\text { - Signs of limb ischemia } \\
\text { - } \text { Arthritis }\end{array}$ \\
\hline $\begin{array}{l}\text { Laboratory } \\
\text { findings }\end{array}$ & $\begin{array}{l}\text { - Elevation of acute phase reactants (ESR and CRP) } \\
\text { - Anemia }\end{array}$ & $\begin{array}{l}\text { - Elevation of acute phase reactants (ESR and CRP) } \\
\text { - Anemia }\end{array}$ \\
\hline \multicolumn{3}{|c|}{ Suspicion of disease relapse } \\
\hline & GCA & TAK \\
\hline Symptoms & $\begin{array}{l}\text { - Return of constitutional Symptoms (weight loss, } \\
\text { fever, night sweats, } \\
\text { - New/recurrent PMR symptoms } \\
\text { - Visual changes } \\
\text { - Return of headache symptoms } \\
\text { - Jaw or tongue claudication }\end{array}$ & 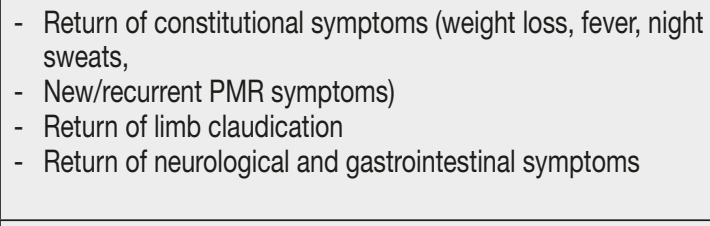 \\
\hline $\begin{array}{l}\text { Findings } \\
\text { on clinical } \\
\text { examination }\end{array}$ & $\begin{array}{l}\text { - New/worsening of tenderness and/or thickening } \\
\text { of the superficial temporal arteries with or without } \\
\text { reduced pulsation. } \\
\text { - New/worsening scalp tenderness. } \\
\text { - New/worsening ophthalmoscopic abnormalities }\end{array}$ & $\begin{array}{l}\text { - Absent or weak peripheral pulse(s) and anisosphygmia } \\
\text { - Hypertension (>140/90 mm Hg) }\end{array}$ \\
\hline $\begin{array}{l}\text { Laboratory } \\
\text { findings }\end{array}$ & $\begin{array}{l}\text { - Elevation of acute phase reactants (ESR and CRP) } \\
\text { - Anemia }\end{array}$ & $\begin{array}{l}\text { - Elevation of acute phase reactants (ESR and CRP) } \\
\text { - Anemia }\end{array}$ \\
\hline
\end{tabular}

GCA, Giant cell arteritis; TAK, Takayasu arteritis; ESR, erythrocyte sedimentation rate; CRP, C-reactive protein. PMR, polymyalgia rheumatica; *ophthalmoscopic abnormalities: anterior ischaemic optic neuropathy, oculomotor cranial nerve palsy/palsies, central retinal artery occlusion, branch retinal artery occlusion and/or choroidal ischaemia. 
tively 0.84 and $0.83,0.82$ and 0.83 , and 0.85 and 0.78 (CIs not available). However, the risk of bias of this study was judged to be high and data stratified for GCA were not reported (43). Thus, the current body of evidence on the role of imaging to monitor disease activity in GCA is scarce.

\section{From evidence to recommendation}

Despite the low quality of the evidence, this recommendation was judged to be strong since the clinical judgement is still the current gold standard and the suspicion of relapse and its confirmation are largely based on patient's signs and symptoms as detected by a physician with clinical expertise (Table III). Based on the clinical experience, laboratory analyses consistent with a systemic inflammatory response, usually high ESR and/or CRP, were judged to strongly support the clinical suspicion of active disease similarly to the setting of new diagnosis of GCA. Conversely, the role of PET in disease monitoring still needs to be elucidated. Its use cannot be recommended in most patients and most clinical situations and should be considered on a case-by-case basis, given the results in terms of performance from the afore-mentioned clinical studies.

\section{RECOMMENDATION 4:}

\section{assessment of disease damage in GCA}

A) In patients diagnosed with GCA, the use of imaging (MR angiography, CT angiography or colour-duplex ultrasonography) is strongly recommended for the assessment of structural damage, such as vascular stenosis, occlusion, dilatation and/or aneurysms, as part of patient's follow-up.

B) The choice of the imaging method and the timing of the assessment are conditionally recommended to be scheduled on an individual basis.

QoE: Very Low; SoR: Strong (A) / Conditional (B); LoA mean (sd) 7.0 (2.1).

\section{Supporting evidence}

No diagnostic studies among those retrieved by the systematic review addressed the PICOs relevant to this recommenda- tion. However, the risk of vascular damage is well-known in GCA patients as observed in multiple prognostic studies. The pooled frequency of any large artery complication (including aneurysms, stenosis, and/or dissections of aorta and its branches) was $4.4 \%(95 \%$ CI $4.0-4.90, n=8343)$ from the raw data published in 11 studies (19), but the single-study prevalence ranged widely from 1.4 (19) to $61.1 \%$ (19). In addition, heterogeneous definitions of large artery complications were used, and imaging was neither standardized nor systematically performed. Finally, peripheral arterial occlusive involvement of the limbs was also observed [pooled prevalence 9.7\%, 95\% CI 5.8-14.9, $\mathrm{n}=186$ from 2 studies (19)].

\section{From evidence to recommendation}

Since large artery involvement is associated with an increased risk of death as reported in 2 studies [HR 2.4, 95\% CI 1.6-3.6, $\mathrm{n}=204$ (3), and HR 5.1, 95\% CI 1.3-19.7, $\mathrm{n}=80$ (44)], a high index of suspicion for LVV pathology should be retained by clinicians and the search for vascular damage was strongly recommended in GCA patients. On the other hand, the best imaging as well as the optimal time-schedule for the follow-up of the vascular damage in GCA are still matter of debate and a topic for future research.

\section{RECOMMENDATION 5: assessment of disease activity and damage in TAK}

A) In patients with a diagnosis of TAK and suspicion of relapse, clinical findings and ESR and/or CRP levels are strongly recommended for the assessment of disease activity.

B) The use of imaging (MR angiography, CT angiography, PET or colour-duplex ultrasonography) is strongly recommended for the assessment of disease activity and/or structural damage, such as vascular stenosis, occlusion, dilatation and/or aneurysms, as part of patient's follow-up.

C) The choice of the imaging method and the timing of the assessment are conditionally recommended to be scheduled on an individual basis. 
QoE: Low (A) to Very Low (B, C); SoR; Strong (A, B) / Conditional (C); LoA mean (sd): 7.9 (1.0).

\section{Supporting evidence}

A limited number of studies focused on the performance of laboratory findings to identify a systemic inflammatory response consistent with disease activity: CRP and ESR were mainly investigated. The sensitivity and the specificity of CRP was $0.55(95 \%$ CI $0.43-0.67)$ and 0.74 (95\% CI 0.62-0.86) and of ESR 0.74 (95\% CI 0.56-0.92) and 0.77 (95\% CI 0.66-0.89) from the metanalysis of 3 studies $(n=126)(45-47)$ with consistent results despite the different laboratory cut-offs. From the metanalysis of 11 studies ( $\mathrm{n}=339$ patients) (19), the performance of PET to detect active disease were 0.82 (95\% CI $0.73-0.91)$ and 0.81 (95\% CI $0.69-0.94)$ in terms of sensitivity and specificity, respectively. However, the inconsistency of studies' results was statistically significant and substantial and heterogeneous scores based on visual grading or several Standardized Uptake Value (SUV) cut-offs were tested and multiple clinical definitions as gold standard were used to define the disease as active. The body of evidence from 5 studies $(\mathrm{n}=305)$ (19) on the role of carotid ultrasonography (with or without contrast enhancement) showed that sensitivity was $0.61(95 \% \mathrm{CI}$ $0.37-0.84)$ and specificity was $0.73(95 \%$ CI 0.52-0.94), but the inconsistency of the results and the heterogeneity of definitions and imaging methods were a major issue. The systematic search did not retrieve any study on the diagnostic performance of MRA and CTA to detect disease activity. Comparative studies between imaging techniques for the monitoring of vascular damage due to disease were not found, as well.

\section{From evidence to recommendation}

The strength of this recommendation was mostly judged on the basis of the panel's clinical experience since the evidence on the role of laboratory tests and imaging was low-quality or lacking. The key clinical signs and symptoms consistent with a suspicion of disease relapse are listed in Table III. Vascular damage of large arteries is known to be a severe feature of TAK, but data on the determinants of its occurrence are insufficient to frame a recommendation on the frequency of imaging assessment, which should be conditional to the individual characteristics of the patient.

\section{Recommendations for treatment}

\section{RECOMMENDATION 6:} induction of remission

In active $\mathrm{GCA}^{\S}$ or $\mathrm{TAK}^{\dagger}$, the prompt commencement of high dose of oral glucocorticoids (40-60 mg prednisone-equivalent per day) is strongly recommended to induce clinical remission.

QoE: Moderate ${ }^{\S}$ to Very Low ${ }^{\dagger}$; SoR: Strong; LoA mean (sd): 8.2 (1.2).

\section{Supporting evidence}

The SLR retrieved four randomized controlled trials (RCTs) assessing GCs in GCA (48-51). Two of them investigated the GCs-sparing effect of high-dose pulse intravenous methylprednisolone induction therapy. Of note, patients with ocular manifestations were excluded. However, GCs regimen was different among the studies: $15 \mathrm{mg} / \mathrm{kg}$ intravenous methylprednisolone for 3 days followed by $40 \mathrm{mg} /$ day oral prednisone (49) or $240 \mathrm{mg}$ intravenous single pulse of methylprednisolone, followed by $0.5-0.7 \mathrm{mg} / \mathrm{kg} /$ day oral prednisone (51). Only the study by Mazlumzadeh et al. met the primary endpoint, in which high-dose pulse intravenous allowed a more rapid oral GC tapering, a lower median daily dose of prednisolone at week $78(\mathrm{p}=0.0004)$ and higher sustained remission after treatment discontinuation $(p=0.006)$ (49). In a retrospective analysis on 103 GCA patients, induction of remission with methylprednisolone pulses predicted a better response (HR $2.21 ; 95 \%$ CI 1.31 to 3.71 ) (19).

There are no clinical trials comparing different initial oral GC doses for GCA, the available data deriving from observational studies with no strong conclusive evidence. In a retrospective review of 286 biopsyproven GCA patients, a higher initial oral 
prednisone dose ( $>40 \mathrm{mg} /$ day) was associated with a higher likelihood of reaching a low dose sooner (HR 1.46; 95\%CI 1.09 to 1.96 ) and discontinuing GCs earlier (HR 1.56 ; $95 \%$ CI 1.09 to 2.23 ) (19).

Clinical trials have not been conducted in patients with ocular manifestations, but observational data indicate that the majority of visual loss in GCA occurs before initiation of GC therapy. In a retrospective longitudinal study comparing the route of GCs administration during the first week of treatment on visual loss, there was an increased likelihood for improved visual acuity in the group treated with intravenous GCs (40\%) compared with the oral route (13\%) (19). The SLR did not retrieve any study focusing on the role of GCs in TAK.

\section{From evidence to recommendation}

In summary, prompt initiation of GC therapy in GCA is consistently associated with a better outcome, including visual complications. Only low to moderate quality data are available on the most appropriate initial dose and route of administration.

There may possibly be a small benefit in terms of a decreased cumulative dose of GC in patients treated with GC intravenous pulse therapy, but the role of intravenous GCs in patients with acute visual loss still remains uncertain.

However, clinical experience suggests that most GCA and TAK patients respond symptomatically to a 40-60 $\mathrm{mg}$ daily dose of prednisolone within 1-7 days, therefore this recommendation was judged to be strong by the panellists.

\section{RECOMMENDATION 7:}

\section{fast-track approach in suspected} cranial GCA

In patients suspected to have cranial GCA, the fast-track pathway, based on quick clinical and ultrasonographic evaluation, is conditionally recommended in order to reduce the risk of permanent visual impairment. The implementation of fast-track pathway should not delay the initiation of the treatment.

QoE: Moderate; SoR: Conditional; LoA mean (sd): 7.7 (1.3).
Supporting evidence

When GCA is suspected, GCs should be promptly initiated by primary care providers alongside an immediate referral to the local GCA expert team pathway.

In two recent retrospective reports from centres that have set up fast-track referral pathways, initial diagnostic evaluation and treatment of patients with suspected GCA within $24 \mathrm{~h}$ of referral has been associated with a significant reduction in rates of visual loss, inpatient costs and need for temporal artery biopsy (pooled disease remission RR $0.22,95 \%$ CI 0.09 to 0.52 ) ( 52 , 53). Moreover, a prospective multicentre cohort study $(\mathrm{n}=381)$ also showed that a fast-track strategy may be accurate and cost-effective (33).

\section{From evidence to recommendation}

GCA is a medical emergency. Rapid specialist assessment is a core GCA management concept, so 'fast-track' referral pathways for urgent specialist assessment of suspected GCA are advantageous. The quality of the evidence was uprated from low to moderate because no serious limitations were observed. However, the fasttrack referral pathways may be not available in all centres and have been, for this reason, conditionally recommended. The referral through fast-track pathways should not delay the initiation of the treatment.

\section{RECOMMENDATION 8:}

\section{treatment of disease relapse}

In patients diagnosed with $\mathrm{GCA}^{\S}$ or $\mathrm{TAK}^{\dagger}$ who experience a disease relapse, the reinstitution or the dose escalation of the glucocorticoid therapy is strongly recommended.

QoE: Moderate ${ }^{\S}$ to Very Low ${ }^{\dagger} ;$ SoR: Strong; LoA mean (sd): 8.4 (0.8).

\section{Supporting evidence}

A relapse rate of $34-75 \%$ (according to the different definitions for relapse) in patients with GCA treated with GCs has been reported by several large observational cohort studies. Two RCTs of TAK patients with protocolized GCs tapering $(54,55)$, reported a relapse rate of $60-80 \%$ in the GC 
monotherapy arm. In all studies retrieved by the SLR, the most effective tapering schedule was not specifically evaluated. In one RCT (48) and one prospective study (56) conducted on GCA patients, prompt reinstitution or dose increase of GCs at the time of relapse resulted in rapid symptoms improvement (pooled risk of relapse RR $0.4095 \%$ CI 0.15 to 1.07 ) (19).

The SLR did not retrieve any study focusing on the optimal glucocorticoid dose in case of relapse in patients with TAK.

\section{From evidence to recommendation}

Relapses in GCA and TAK are common events. Most relapses occurred during GC monotherapy, with increasing risk at lower doses ( $\leq 10 \mathrm{mg} /$ day) (57). Regardless of the moderate quality of the evidence, this recommendation was judged to be strong by the panellists.

Relapses, which may lead to impellent organ damage, should be treated with highdose GC like new onset disease. Otherwise, an increase of daily GC dose to the last effective dose should be considered. However, it has to be pointed out that each relapse requiring a reinstitution or a doseincrease of GCs, results in higher cumulative $\mathrm{GC}$ exposure which leads to an increased risk of GC-related adverse effects.

\section{RECOMMENDATION 9: conventional and biological DMARDs in GCA}

In selected patients with GCA with refractory or relapsing disease or at risk of glucocorticoid related adverse effects, the use of adjunctive DMARDs (tocilizumab or methotrexate) is strongly recommended. QoE: Moderate; SoR: Strong; LoA mean (sd): 7.7 (0.8).

\section{Supporting evidence}

Three RCTs were conducted in newly diagnosed GCA patients, evaluating the role of methotrexate (MTX) in addition to GCs (58-60). Only one met the primary endpoint: adding MTX resulted in significant reduction in relapses and cumulative GCs dose (60). A high-quality meta-analysis pooling data from the three RCTs showed the ef- ficacy of MTX in reducing first (HR 0.65; $95 \%$ CI 0.44 to 0.98 ) and second (HR 0.49; $95 \%$ CI 0.44 to 0.98 ) disease relapses (61). Accordingly, pooled data from three observational studies confirmed a decreased disease relapse risk at 48 weeks: RR 0.75 $95 \%$ CI 0.63 to 0.89 (19). Moreover, MTX resulted in a reduction in the cumulative GC dose by $506.6(-1186.4 ; 2199.5) \mathrm{mg}$ at 48 weeks, however not significant when compared to GC monotherapy.

The effectiveness of MTX has been evaluated in two observational retrospective studies. The first one had a long follow-up time (up to 8.4 years) and MTX proved to be safe and with good retention rate (19). In the second one, each GCA patient treated with MTX was matched with a GCA treated with GC monotherapy (19). The addition of MTX decreased the subsequent relapse rate by nearly 2 -fold but did not demonstrate a GC sparing effect.

In two open RCTs, including newly diagnosed and refractory cases of GCA, cyclosporine was not effective and did not show a GC sparing effect (19). The efficacy of azathioprine was tested in one RCT, resulting in significantly less GC cumulative dose at week 52, but with major methodological issues affecting the study outcomes (19). In an open prospective randomized trial, dapsone was tested versus GC monotherapy, but without reaching significant results (19). The efficacy and safety of leflunomide and cyclophosphamide (19) were evaluated only in open-label retrospective cohort studies and did not allow for definite conclusions.

The SLR retrieved two RCTs assessing tocilizumab (TCZ) in newly diagnosed and relapsing GCA patients $(62,63)$. A phase II study compared the effects of TCZ, given intravenously $8 \mathrm{mg} / \mathrm{kg}$ every 4 weeks, with placebo (63). In the treatment group (20 patients), $85 \%$ achieved sustained remission for 1 year, compared with $20 \%$ in the placebo group (10 patients). A phase III study, which comprised a total of 251 patients, compared the effects of tocilizumab 162 mg subcutaneously every week or every other week with a placebo (62). Prednisolone was administered according to a taper- 
ing schedule for 26 weeks (both TCZ arms and placebo arm) or for 52 weeks (placebo arm). Percentages of sustained remission at 1 -year follow-up were $56 \%$ (TCZ every week) and 53\% (TCZ every other week) in the treatment arms, and $14 \%$ (prednisolone reduction schedule for 26 weeks) and $18 \%$ (prednisolone reduction schedule for 52 weeks). Finally, a reduction in the cumulative GC dose was observed in the TCZ treatment arms (1862 mg compared with $3818 \mathrm{mg}$ for the 52 -week taper and $3296 \mathrm{mg}$ for the 26-week taper, $\mathrm{p}<0.001$ ). Pooled risk of remission at week 52, resulting from the phase II and phase III RCTs: RR 2.21 95\%CI 1.42 to 3.44. Effectiveness of intravenous TCZ was demonstrated also in three retrospective open-label studies and two case series (19).

Abatacept was studied in a single, small $\mathrm{RCT}$, in which patients received abatacept initially in addition to GC therapy (19). A marginally significant reduction in the risk of relapse (relapse-free survival rate at 12 months: $48 \%$ vs $31 \%$; $p=0.049$ ) was demonstrated, but a post hoc analysis to compare the proportion of patients in remission at 12 months did not show a significant difference between the treatment arms (RR $1.5095 \%$ CI 0.71 to 3.17 ). Three multicentre, double-blind placebo-controlled RCTs of tumour necrosis factor (TNF) inhibitors (adalimumab, etanercept and infliximab) were conducted in GCA patients (19). None of the studies demonstrated efficacy in terms of disease relapse, reduction of GCs and GC-sparing effect. Finally, in 14 patients with refractory GCA, the steroidsparing effect of ustekinumab was reported, showing GC dose reduction from baseline to last follow-up ( 20 to $5 \mathrm{mg}$ /day; $\mathrm{p}=0.001$ ) (19). However, this study did not have a control arm group and in a recent openlabel trial ustekinumab was well tolerated, but did not prevent disease relapse in a significant proportion of GCA patients (64). The right time to start a DMARD in addition to GCs is currently still a matter of debate. It is noteworthy that in a recent multicentre retrospective study $(n=165)$, the early (i.e. $<3$ months) introduction of immunosuppressive therapies (either MTX,
TCZ, or cyclophosphamide) was associated with a lower incidence of steroid-induced diabetes compared to GCA patients who received GC only or an immunosuppressive therapy more than 3 months later (65).

\section{From evidence to recommendation}

Although the risk of relapse in GCA is high, a considerable number of GCA patients treated with GC monotherapy do not relapse and are able to taper the GC dose. The panellists agreed to strongly recommend the use of adjunctive therapy in patients who have already developed or have either an increased risk of developing GCrelated side effects or complications, or for relapsing patients irrespective of other risk factors. The decision to use adjunctive immunosuppressive therapy should be balanced against potential risks for treatmentrelated complications.

In summary, MTX may reduce the risk of relapse and GC exposure in GCA patients. Other conventional synthetic disease modifying anti-rheumatic drugs (csDMARDs) are not supported by enough high-quality evidence. Among biological immunosuppressive drugs, TCZ proved to be effective in achieving remission, preventing disease flares and reducing GC cumulative dose in newly diagnosed and relapsing GCA patients.

There are no trials comparing TCZ and MTX in GCA and clear data about the superiority of one agent over the other are not available. However, compared with MTX, the effect size of TCZ in terms of relapse risk reduction and GC sparing seems larger. Therefore, the panellists recommend the use of TCZ over MTX in GCA patients, on an individual basis.

\section{RECOMMENDATION 10: conventional and biological DMARDs in TAK}

In all patients diagnosed with TAK, the use of adjunctive therapies, such as conventional synthetic or biological DMARDs, in combination with GCs is conditionally recommended.

QoE: Very Low; SoR: Conditional; LoA mean (sd): 7.5 (2.1). 
Supporting evidence

There are no RCTs retrieved by the SLR on csDMARDs for TAK. One open label prospective study assessed the role of MTX as adjunctive therapy in TAK, demonstrating a possible role in inducing and maintaining remission (19). Three studies (two prospective and one retrospective) analysed the efficacy of mycophenolate mofetil in patients with TAK, resulting in improvement in disease activity, significant reduction in acute phase reactants and steroid-sparing ability (19). Cyclophosphamide proved a mild efficacy in haltering angiographic progression in a prospective study, compared with MTX (19). Similarly, azathioprine was associated with an improvement in systemic symptoms and acute phase reactants in a prospective open-label study (19). Finally, leflunomide was assessed by two observational studies. In the first one leflunomide was associated with sustained remission in about half of the patients with good safety profile, but only 5 out of 12 patients included remained on leflunomide after a mean of 12 months of follow-up (19). In the second one, leflunomide was administered to both naïve treatment patients and cyclophosphamide refractory patients, leading to a rapid induction and sustained remission, including acute phase reactants (19).

The efficacy and safety of TCZ $162 \mathrm{mg}$ subcutaneously in relapsing TAK patients was evaluated in a double-blind, placebocontrolled RCT (66). Primary endpoint (time to relapse) was not met, however in the per protocol set, TCZ resulted effective (HR 0.34, 95\%CI 0.11-1.00). Intravenous TCZ in refractory TAK was tested in six studies, suggesting clinical effectiveness but with radiological worsening in a fair share of patients and only a temporary effect of treatment, with relapses occurring on drug discontinuation (19).

Abatacept was assessed in a double-blind, placebo-controlled RCT (19). In newly diagnosed or relapsing TAK patients, abatacept did not reduce relapse risk and did not show any GC sparing effect. Eight retrospective observational studies were retrieved by the SLR, assessing the role of TNF inhibitors (infliximab, etanercept, adalimumab), mainly in refractory TAK not responding to previous treatment, demonstrating an overall benefit, but with poor evidence and a radiological progression in a minority of patients (19). Only one case series reported the use of rituximab in 7 refractory TAK patients, but $4 / 7$ still had persistent disease at follow-up (19).

\section{From evidence to recommendation}

There is no high-quality evidence regarding the use of csDMARDs in TAK, because only uncontrolled prospective and retrospective case series are available. There are no trials comparing csDMARDs and biologic drugs and no clear assumption about the superiority could be drawn. However, overall evidence for biologic drugs favours the use of TCZ and TNF inhibitors in relapsing/refractory disease. Despite the very low quality of evidence, the panellists recommended an early administration of a GC-sparing agent in TAK. The final choice should be decided on an individual basis.

\section{RECOMMENDATION 11: use of antiplatelet or cholesterol-lowering agents in GCA}

In patients with GCA, the routine prescription of antiplatelet or cholesterol-lowering agents, such as statins, unless necessary for the cardiovascular risk, is conditionally not recommended.

QoE: Very low; SoR: Conditional; LoA mean (sd): 7.0 (2.4).

\section{Supporting evidence}

Seven observational cohort studies investigating the role of antiplatelet agents to prevent ischaemic complication in GCA were retrieved by the SLR (19). The results were controversial, with a pooled RR for ischaemic events of $1.1(95 \% \mathrm{CI} 0.72$ to 1.67) (19). The studies had a high heterogeneity and very serious risk of bias. No RCTs were identified.

Contradictory results on the role of statins in GCA were obtained from four observational studies. Two of them showed that statins, given prior to or within 1 year from the diagnosis of GCA, were associated with reduced cardiovascular events but no ef- 
fect on the inflammatory process or on GC tapering (pooled RR for disease relapse of 0.94 95\%CI 0.42-2.10) (19). The others did not demonstrate any reduction in the incidence of severe ischaemia or cranial ischemic events, both for statins and antiplatelet agents (pooled RR for cranial ischemic events of $1.4695 \% \mathrm{CI} 0.54-3.93$ and $1.1095 \%$ CI 0.72-1.67, respectively) (19).

\section{From evidence to recommendation}

The risk of experiencing cardiovascular and cerebrovascular events is increased in patients with GCA. However, the role of antiplatelet or cholesterol-lowering agents is controversial, and the quality of evidence is very low, with RCTs still lacking. The panellists agreed to recommend that antiplatelet or anticoagulant therapy should not be routinely prescribed unless they are indicated for other reasons (e.g., coronary heart disease, cerebrovascular disease, etc.). Other adjunctive therapy and prophylaxis, namely prevention and treatment of osteoporosis, hypertension, infectious complications, and role of vaccinations were not assessed specifically for GCA. The panellists suggested to refer to the relevant international recommendations in rheumatic diseases, which have been published so far.

\section{RECOMMENDATION 12: \\ revascularization procedures in TAK}

In patients diagnosed with TAK, revascularization procedures (open surgery or endovascular procedures) are conditionally recommended in phase of stable remission. QoE: Very Low; SoR: Conditional; LoA mean (sd): 7.6 (1.8).

\section{Supporting evidence}

The SLR retrieved several retrospective observational studies on surgical management of arterial stenosis in TAK, with wide range of baseline characteristics, different vascular sites and broad spectrum of concomitant medical treatment. The main indication for surgery was symptomatic arterial stenosis, with symptoms depending on the different involved vascular site.

Pooled results of five observational studies show that open surgery can yield better results in term of long-term durability and patency rate compared with the endovascular approach (RR 1.74 95\%CI 1.24-2.46), but with higher morbidity and potential damage (RR 2.99 95\%CI 1.44-6.24) (19).

Restenosis has been described in 17-60\% of patients, and it was usually higher for stenting procedures compared with angioplasty (pooled RR 2.76 95\%CI 1.40-5.42), but with the latter being associated to higher acute vascular complications (19).

Interventions performed during a stable stage of the disease (restenosis HR 0.30, $95 \% \mathrm{CI}$ not reported) and followed by GCs and immunosuppressive agents (restenosis HR $0.41,95 \%$ CI not reported) have been documented to be independent variables for arterial patency following surgical procedures for any site of vascular involvement (19).

Surgical therapy aiming at definitive repair of aneurysms in TAK has been demonstrated to give better results compared to conservative procedures, which are characterized by higher rate of recurrence without ensuring a radical surgical resolution of the lesion (19).

\section{From evidence to recommendation}

In summary, despite low to very low quality of evidence, the panellists agreed to support the use of revascularisation techniques both for stenosis and aneurysm in TAK patients. Disease remission or perioperative GC treatment for inflammation control is crucial. As for the preferred surgical procedure, it depends on anatomic vascular location, timing (elective or emergency) and other factors. Balloon angioplasty appeared superior to stenting for arterial stenosis interventions even though the restenosis rate was quite similar. In case of urgency, revascularization procedures should be evaluated on a case-by-case basis.

\section{Prognosis assessment}

The overall evidence was judged to be insufficient in terms of quality to stratify LVV patients to frame recommendations on personalized risk management both for GCA and for TAK patients. However, clinicians may consider a number of disease 
features when managing individual patients with LVV.

In GCA patients, several risk factors were found to be relevant for multiple disease outcome. Particularly, visual loss was associated with older age, history of amaurosis, jaw claudication, risk factors for atherosclerosis, while male gender, large vessel involvement, hyperlipidaemia, and smoking were found to be risk factors for aortic aneurysm (19). Moreover, large-vessel involvement was associated with a prolonged GC treatment course (19). Finally, the histological features of GCA might be considered, but their clinical impact still remains matter of debate.

In TAK patients, prognostic studies were sporadic. Male gender was found to be related to increased risk for vascular damage (any large artery complication) and high blood pressure (19).

In every LVV patients, the presence of comorbidities, such as diabetes mellitus, hypertension and osteoporosis need to be regularly checked due to their prognostic relevance and to the treatment with GCs.

\section{DISCUSSION}

Since the 2012 SIR guidelines for the management of primary large-vessel vasculitis, new evidence has become available, including high-quality diagnostic studies and several RCTs. This has expanded our understanding about LVV and has provided a valuable foundation for a significant update of the original recommendations.

The following revised recommendations differ in several aspects from the 2012 SIR guidelines for primary large-vessel vasculitis (17). First, the methodology of the GRADE-ADOLOPMENT was applied (18), and clinical practice guidelines endorsed by reference scientific societies were considered. This helped to generate an updated comprehensive guideline tailored to the Italian scenario. After the ADAPTE experience (67), the GRADEADOLOPMENT methodology was chosen due to its advantages in terms of reducing the need for funds, workload and human resources when compared to develop- ing a de novo guideline. As several LVV guidelines have been published, such a systematic strategy was adopted to identify, appraise, synthesize, and customize the existing international guidelines to suit the Italian healthcare setting. Secondly, new recommendations were added with regards to diagnosis, management and follow-up. Guidance of the management of LVV patients in clinical practice was evaluated to foster the early identification and management of the patients suitable for treatment, from the first-line treatment decision to the follow-up. While the 2012 SIR guidelines focused primarily on the use of biological agents in patients with LVV, this updated version included new recommendations to address the use of GCs, cDMARDs and bDMARDs.

In line with the EULAR 2018 recommendations (11), the strategy of personalized therapy according to disease phenotype and the presence of comorbidities was considered. The importance of comorbidity in terms of management at diagnosis of LVV and subsequent monitoring was highlighted since comorbidities are major determinants of choice of therapy (mainly $\mathrm{GCs}$ ), prognosis and life quality expectancy in these patients. Thus, a multidisciplinary approach should be pursued. When compared to the 2018 EULAR version, the mainstay of treatment was overall unchanged. Some aspects, including the timing of treatment, the choice of the first-line and the second-line treatment were specified. The GRADE-ADOLOPMENT methodology was also applied in the latest 2021 ACR guidelines (16), which provide guidance regarding the diagnosis and treatment of LVV patients, resembling the European recommendations. Some differences should be noted, including the preference, in the United States, for temporal artery biopsy over cranial imaging studies for the diagnosis of GCA and for combining glucocorticoids with a glucocorticoid-sparing agent as initial treatment of GCA. In the last 3 years, the Swedish Society of Rheumatology and the British Society of Rheumatology produced guidelines for investigation, treatment, and follow-up of LVV. 
When compared to these revised CGPs, no major discrepancies were found in terms of retrieved literature and overarching principles underlying these recommendations.

However, these clinical practice guidelines have some limitations. Firstly, the last update of the literature search is conditional to the end-of-search date (February $25^{\text {th }}$, 2020) and any further evidence was not evaluated. However, at the time of writing this report, these recommendations are the most updated available in the literature. Secondly, studies addressing health economic evaluations are scarce, limiting the availability of robust evidence to guide approaches. However, when supported by available data, the aspects of efficiency and effectiveness of specific strategies were considered throughout these guidelines to suit the Italian healthcare setting. Finally, most of the recommendations are based on low or very low quality of evidence, mainly due to the rare prevalence of these diseases and the difficulty to perform trials on LVV. Nevertheless, these aspects are counterbalanced by the overall strength of the recommendations on the basis of a robust clinical experience.

\section{Auditing}

An audit tool based on questions for patients and the attending physicians will be implemented in a sample of referral centres managing LVV as part of their clinical practice to check that SIR guidelines is being adhered to.

\section{Plans of update}

The need for update of these recommendations will be assessed after 3 years. In case of major publications from novel evidence, a partial or complete revision may be triggered.

\section{Disclosure statements}

The conflict of interest was managed by filling in the forms published in the handbook for the development of clinical practice guidelines for the National Guidelines System (revision 1.3.1 February 2019). Disclosure statements were collected in January 2020 and updated in January 2021 if relevant changes were reported. N. Ughi reported a grant from SIR for these recommendations and consulting fees from Roche outside these recommendations; C. Crotti, R. Padoan, and S. Sciascia reported a grant from SIR for these recommendations; G. Carrara, A. Zanetti, and D. Rozza reported honoraria from SIR; G. Emmi reported financial support to participate to a workshop and consulting fee from Roche outside these recommendations; S. Monti reported a fee for lecture from Roche outside these recommendations; L. Quartuccio, D. Camellino, S. Morbelli, F. Muratore, S. Tonolo, K. El Aoufy, R. Caporali, S. De Vita, C. Salvarani, M.A. Cimmino reported nothing to disclose.

\section{Acknowledgements}

The Authors acknowledge all those who made contribution as stakeholders (A. Alberti, E. Bartoloni Bocci, J Blagojevic, M. Bond, R. Bortolotti, M. Colaci, E. Conticini, C. Dejaco, G. Di Scala, A. Giollo, M. Govoni, A. Hoxha, A. Ianniello, M. Mosca, C. Nannini, G. Paolazzi, N. Pipitone, F. Regola, R. Rinaldi, L. Santo, F. Schiavon, A. Tomelleri) and the referees for the external revision (C.A. Sciré, C Rossetti, C. Manzo).

\section{Author Contributions}

All authors were involved in drafting the article or revising it critically for important intellectual content, and all authors approved the final version to be published. Conception and design: N. Ughi, C. Crotti, R. Padoan, S. Sciascia. Systematic review search: N. Ughi, C. Crotti, R. Padoan, S. Sciascia. Meta-analysis: G. Carrara, A. Zanetti, D. Rozza.

Critical appraisal of the scientific evidence: N. Ughi, C. Crotti, R. Padoan, S. Sciascia, M.A. Cimmino, S. Monti, D. Camellino, F. Muratore, G. Emmi, S. Morbelli, K. El Aoufy, S. Tonolo, L. Quartuccio, R. Caporali, S. De Vita, C. Salvarani.

Wording and discussion of the recommendations: N. Ughi, C. Crotti, R. Padoan, S. Sciascia, M.A. Cimmino, S. Monti, D. Camellino, F. Muratore, G. Emmi, S. Morbelli, K. El Aoufy, S. Tonolo, R. Caporali, S. De Vita, C. Salvarani. 


\section{Funding}

The Italian Society of Rheumatology provided financial support, as well as noneconomic support (e.g. meeting rooms, secretariat services) for this recommendations to carry out the work described in this manuscript and without affecting the content of this guideline. No direct funding was received by any public body or commercial organisation.

\section{REFERENCES}

1. Fries JF, Hunder GG, Bloch DA, et al. The American College of Rheumatology 1990 criteria for the classification of vasculitis. Summary. Arthritis Rheum. 1990; 33: 1135-6.

2. Jennette JC, Falk RJ, Bacon PA, et al. 2012 revised International Chapel Hill Consensus Conference Nomenclature of Vasculitides. Arthritis Rheum. 2013; 65: 1-11.

3. Kermani TA, Warrington KJ, Crowson CS, et al. Large-vessel involvement in giant cell arteritis: a population-based cohort study of the incidence-trends and prognosis. Ann Rheum Dis. 2013; 72: 1989-94.

4. Li KJ, Semenov D, Turk M, Pope J. A metaanalysis of the epidemiology of giant cell arteritis across time and space. Arthritis Res Ther. 2021; 23: 82.

5. Mohammad AJ, Nilsson JÅ, Jacobsson LTH, et al. Incidence and mortality rates of biopsyproven giant cell arteritis in southern Sweden. Ann Rheum Dis. 2015; 74: 993-7.

6. Petri H, Nevitt A, Sarsour K, Napalkov P, Collinson N. Incidence of giant cell arteritis and characteristics of patients: data-driven analysis of comorbidities. Arthritis Care Res (Hoboken). 2015; 67: 390-5.

7. Catanoso M, Macchioni P, Boiardi L, et al. Incidence, Prevalence, and Survival of BiopsyProven Giant Cell Arteritis in Northern Italy During a 26-Year Period. Arthritis Care Res (Hoboken). 2017; 69: 430-8.

8. Koide K. Takayasu arteritis in Japan. Heart Vessels Suppl. 1992; 7: 48-54.

9. Mohammad AJ, Mandl T. Takayasu arteritis in Southern Sweden. J Rheumatol 2015; 42: 853-8.

10. Watanabe Y, Miyata T, Tanemoto K. Current clinical features of new patients with takayasu arteritis observed from cross-country research in Japan: Age and sex specificity. Circulation. 2015; 132: 1701-9.

11. Hellmich B, Agueda A, Monti S, et al. 2018 Update of the EULAR recommendations for the management of large vessel vasculitis. Ann Rheum Dis. 2020; 79: 19-130.

12. MacKie SL, Dejaco C, Appenzeller S, et al. British Society for Rheumatology guideline on diagnosis and treatment of giant cell arteritis. Rheumatol (United Kingdom). 2020; 59: E1-23.

13. Bienvenu B, Ly KH, Lambert M, et al. Management of giant cell arteritis: Recommendations of the French Study Group for Large Vessel Vasculitis (GEFA). Rev Med Interne. 2016; 37: 154-65.

14. Turesson C, Börjesson O, Larsson K, et al. Swedish Society of Rheumatology 2018 guidelines for investigation, treatment, and follow-up of giant cell arteritis. Scand J Rheumatol. 2019; 48: 259-65.

15. Dejaco C, Ramiro S, Duftner C, et al. EULAR recommendations for the use of imaging in large vessel vasculitis in clinical practice. Ann Rheum Dis. 2018; 77: 636-43.

16. Maz M, Chung SA, Abril A, et al. 2021 American College of Rheumatology/Vasculitis Foundation Guideline for the Management of Giant Cell Arteritis and Takayasu Arteritis. Arthritis Rheumatol (Hoboken, NJ). 2021; 73 : 1349-65.

17. Pipitone N, Olivieri I, Salvarani C. Italian Society of Rheumatology. Recommendations of the Italian Society of Rheumatology for the treatment of the primary large-vessel vasculitis with biological agents. Clin Exp Rheumatol. 2012; 30: S139-61.

18. Schünemann HJ, Wiercioch W, Brozek J, et al. GRADE Evidence to Decision (EtD) frameworks for adoption, adaptation, and de novo development of trustworthy recommendations: GRADE-ADOLOPMENT. J Clin Epidemiol. 2017; 81: 101-10.

19. ISS-SNLG. Available from: https://snlg.iss.it/ wp-content/uploads/2021/08/LG-342-Diagnosi-e-trattamento-vasculiti-grossi-vasi_def

20. Duftner C, Dejaco C, Sepriano A, et al. Imaging in diagnosis, outcome prediction and monitoring of large vessel vasculitis: A systematic literature review and meta-Analysis informing the EULAR recommendations. RMD Open. 2018; 4.

21. Agueda AF, Monti S, Luqmani RA, et al. Management of Takayasu arteritis: A systematic literature review informing the 2018 update of the EULAR recommendation for the management of large vessel vasculitis. RMD Open. 2019; 5.

22. Monti S, Águeda AF, Luqmani RA, et al. Systematic literature review informing the 2018 update of the EULAR recommendation for the management of large vessel vasculitis: Focus on giant cell arteritis. RMD Open. 2019; 5.

23. Brouwers MC, Kho ME, Browman GP, et al. AGREE II: Advancing guideline development, reporting, and evaluation in health care. Prev Med (Baltim). 2010; 51: 421-4.

24. Whiting PF, Rutjes AWS, Westwood ME, et al. Quadas-2: A revised tool for the quality as- 
sessment of diagnostic accuracy studies. Ann Intern Med. 2011; 155: 529-36.

25. Sterne JA, Hernán MA, Reeves BC, et al. ROBINS-I: A tool for assessing risk of bias in non-randomised studies of interventions. BMJ. 2016; 355.

26. Sterne JAC, Savović J, Page MJ, et al. RoB 2: A revised tool for assessing risk of bias in randomised trials. BMJ. 2019; 366.

27. Hayden JA, van der Windt DA, Cartwright JL, et al. Assessing bias in studies of prognostic factors. Ann Intern Med. 2013; 158: 280-6.

28. Ball EL, Walsh SR, Tang TY, et al. Role of ultrasonography in the diagnosis of temporal arteritis. Br J Surg. 2010; 97: 1765-71.

29. Ješe R, Rotar Ž, Tomšiĉ M, Hoĉevar A. The role of colour doppler ultrasonography of facial and occipital arteries in patients with giant cell arteritis: A prospective study. Eur J Radiol. 2017; 95: 9-12.

30. Schmidt WA, Seifert A, Gromnica-ihle E, et al. Ultrasound of proximal upper extremity arteries to increase the diagnostic yield in large-vessel giant cell arteritis. Rheumatology. 2008; 47: 96-101.

31. Pérez López J, Solans Laqué R, Bosch Gil JA, et al. Colour-duplex ultrasonography of the temporal and ophthalmic arteries in the diagnosis and follow-up of giant cell arteritis. Clin Exp Rheumatol. 2009; 27.

32. Karassa FB, Matsagas MI, Schmidt WA, Ioannidis JPA. Meta-analysis: test performance of ultrasonography for giant-cell arteritis. Ann Intern Med. 2005; 142: 359-69.

33. Luqmani R, Lee E, Singh S, et al. The role of ultrasound compared to biopsy of temporal arteries in the diagnosis and treatment of giant cell arteritis (TABUL): A diagnostic accuracy and cost-effectiveness study. Health Technol Assess (Rockv). 2016; 20: 1-270.

34. Chrysidis S, Døhn UM, Terslev L, et al. Diagnostic accuracy of vascular ultrasound in patients with suspected giant cell arteritis (EUREKA): a prospective, multicentre, noninterventional, cohort study. Lancet Rheumatol. 2021; 0 .

35. Bley TA, Uhl M, Carew J, et al. Diagnostic value of high-resolution MR imaging in giant cell arteritis. AJNR Am J Neuroradiol. 2007; 28: 1722-7.

36. Franke P, Markl M, Heinzelmann S, Vaith $\mathrm{P}$, et al. Evaluation of a 32-channel versus a 12-channel head coil for high-resolution postcontrast MRI in giant cell arteritis (GCA) at 3T. Eur J Radiol. 2014; 83: 1875-80.

37. Klink T, Geiger J, Both M, et al. Giant cell arteritis: diagnostic accuracy of MR imaging of superficial cranial arteries in initial diagnosis-results from a multicenter trial. Radiology. 2014; 273: 844-52.

38. Poillon G, Collin A, Benhamou Y, et al. In- creased diagnostic accuracy of giant cell arteritis using three-dimensional fat-saturated contrast-enhanced vessel-wall magnetic resonance imaging at 3 T. Eur Radiol. 2020; 30: 1866-75.

39. Rhéaume M, Rebello R, Pagnoux C, et al. High-Resolution Magnetic Resonance Imaging of Scalp Arteries for the Diagnosis of Giant Cell Arteritis: Results of a Prospective Cohort Study. Arthritis Rheumatol. 2017; 69: 161-8.

40. Nielsen BD, Gormsen LC, Hansen IT, et al. Three days of high-dose glucocorticoid treatment attenuates large-vessel 18F-FDG uptake in large-vessel giant cell arteritis but with a limited impact on diagnostic accuracy. Eur J Nucl Med Mol Imaging. 2018; 45: 1119-28.

41. Nielsen BD, Hansen IT, Keller KK, et al. Diagnostic accuracy of ultrasound for detecting large-vessel giant cell arteritis using FDG $\mathrm{PET} / \mathrm{CT}$ as the reference. Rheumatology (Oxford). 2020; 59: 2062-73.

42. Grayson PC, Alehashemi S, Bagheri AA, et al. 18F-Fluorodeoxyglucose-Positron Emission Tomography As an Imaging Biomarker in a Prospective, Longitudinal Cohort of Patients With Large Vessel Vasculitis. Arthritis Rheumatol. 2018; 70: 439-49.

43. Schramm N, Ingenhoff J, Dechant C, et al. Diagnostic accuracy of positron emission tomography for assessment of disease activity in large vessel vasculitis. Int J Rheum Dis. 2019; 22: 1371-7.

44. MacChioni P, Boiardi L, Muratore F, et al. Survival predictors in biopsy-proven giant cell arteritis: A northern Italian population-based study. Rheumatol (United Kingdom). 2019; 58: 609-16.

45. Dagna L, Salvo F, Tiraboschi M, et al. Pentraxin-3 as a marker of disease activity in Takayasu arteritis. Ann Intern Med. 2011; 155: 425-33.

46. Park MC, Lee SW, Park YB, Lee SK. Serum cytokine profiles and their correlations with disease activity in Takayasu's arteritis. Rheumatology. 2006; 45: 545-8.

47. Li ZQ, Zheng ZH, Ding J, et al. Contrast-enhanced ultrasonography for monitoring arterial inflammation in takayasu arteritis. J Rheumatol. 2019; 46: 616-22.

48. Raine C, Stapleton PP, Merinopoulos D, et al. A 26-week feasibility study comparing the efficacy and safety of modified-release prednisone with immediate-release prednisolone in newly diagnosed cases of giant cell arteritis. Int J Rheum Dis. 2018; 21: 285-91.

49. Mazlumzadeh M, Hunder GG, Easley KA, et al. Treatment of giant cell arteritis using induction therapy with high-dose glucocorticoids: A double-blind, placebo-controlled, randomized prospective clinical trial. Arthritis Rheum. 2006; 54: 3310-8. 
50. Cacoub P, Chemlal K, Khalifa P, et al. Deflazacort versus prednisone in patients with giant cell arteritis: Effects on bone mass loss. J Rheumatol. 2001; 28: 2474-9.

51. Chevalet P, Barrier JH, Pottier P, et al. A randomized, multicenter, controlled trial using intravenous pulses of methylprednisolone in the initial treatment of simple forms of giant cell arteritis: a one year followup study of 164 patients. J Rheumatol. 2000; 27: 1484-91.

52. Patil P, Williams M, Maw WW, et al. Fast track pathway reduces sight loss in giant cell arteritis: results of a longitudinal observational cohort study. Clin Exp Rheumatol. 2015; 33: 2-5.

53. Diamantopoulos AP, Haugeberg G, Lindland A, Myklebust $G$. The fast-track ultrasound clinic for early diagnosis of giant cell arteritis significantly reduces permanent visual impairment: Towards a more effective strategy to improve clinical outcome in giant cell arteritis? Rheumatol (United Kingdom). 2016; 55: 66-70.

54. Touma Z, Nawwar R, Hadi U, et al. The use of TNF- $\alpha$ blockers in Cogan's syndrome. Rheumatol Int. 2007; 27: 995-6.

55. Langford CA, Cuthbertson D, Ytterberg SR, et al. A Randomized, Double-Blind Trial of Abatacept (CTLA-4Ig) for the Treatment of Takayasu Arteritis. Arthritis Rheumatol. 2017; 69: 846-53.

56. Kyle V, Hazleman BL. Treatment of polymyalgia rheumatica and giant cell arteritis. I. Steroid regimens in the first two months. Ann Rheum Dis. 1989; 48: 658-61.

57. Kermani TA, Warrington KJ, Cuthbertson D, et al. Disease relapses among patients with giant cell arteritis: A prospective, longitudinal cohort study. J Rheumatol. 2015; 42: 1213-7.

58. Hoffman GS, Cid MC, Hellmann DB, et al. A multicenter, randomized, double-blind, placebo-controlled trial of adjuvant methotrexate treatment for giant cell arteritis. Arthritis Rheum. 2002; 46: 1309-18.
59. Spiera RF, Mitnick HJ, Kupersmith M, et al. trial of methotrexate in the treatment of giant cell arteritis ( GCA ). Trial. 2001; 495-501.

60. Jover JA, Hernández-García C, Morado IC, et al. Combined treatment of giant-cell arteritis with methotrexate and prednisone: A randomized, double-blind, placebo-controlled trial. Ann Intern Med. 2001; 134: 106-14.

61. Mahr AD, Jover JA, Spiera RF, et al. Adjunctive methotrexate for treatment of giant cell arteritis: An individual patient data meta-analysis. Arthritis Rheum. 2007; 56: 2789-97.

62. Stone JH, Tuckwell K, Dimonaco S, et al. Trial of Tocilizumab in Giant-Cell Arteritis. N Engl J Med. 2017; 377: 317-28.

63. Villiger PM, Adler S, Kuchen S, et al. Tocilizumab for induction and maintenance of remission in giant cell arteritis: A phase 2, randomised, double-blind, placebo-controlled trial. Lancet. 2016; 387: 1921-7.

64. Matza MA, Fernandes AD, Stone JH, Unizony $\mathrm{SH}$. Ustekinumab for the Treatment of Giant Cell Arteritis. Arthritis Care Res (Hoboken). Published Online First: 5 April 2020.

65. Quartuccio L, Isola M, Bruno D, et al. Treatment strategy introducing immunosuppressive drugs with glucocorticoids ab initio or very early in giant cell arteritis: A multicenter retrospective controlled study. J Transl Autoimmun. 2020; 3.

66. Nakaoka Y, Isobe M, Takei S, et al. Efficacy and safety of tocilizumab in patients with refractory Takayasu arteritis: results from a randomised, double-blind, placebo-controlled, phase 3 trial in Japan (the TAKT study). Ann Rheum Dis. 2018; 77: 348-54.

67. Manara M, Ughi N, Ariani A, et al. Providing updated guidelines for the management of rheumatic diseases in Italy with the ADAPTE methodology: A project by the Italian society for rheumatology. Reumatismo. 2019; 71: 1-4. 